\title{
El desafío de las aguas de los ríos Torondoy, Castro o San Pedro y Mojaján o Culebra en el sur del lago de Maracaibo (Venezuela), siglos XVII-XVIII
}

The Water Challenge of the Torondoy, Castro or San Pedro and Mojaján or Culebra Rivers in the South of Lake Maracaibo (Venezuela) I7th-I8th Centuries

DOI: $10.22380 / 20274688.449$

Recibido: 4 de enero del 2018

Aprobado: 3 de abril del 2018
LUIS ALBERTO RAMÍREZ MÉNDEZ*

Universidad de los Andes, Mérida, Venezuela luisramirez811@gmail.com

\section{R E S U M $\quad \mathbf{E} \quad \mathbf{N}$}

La investigación se centra en describir y analizar las modificaciones en los cauces de los ríos Torondoy, Castro o San Pedro y Mojaján o Culebra en el sur del lago de Maracaibo (Venezuela); sus periódicas inundaciones; el desastre ocasionado por los movimientos sísmicos de 1673 y 1674; las secuelas de dichos movimientos; el subsiguiente deslave y los sucesivos desbordamientos durante el siglo xvir y la

* Doctor en Historia de la Universidad Central de Venezuela; miembro del Grupo de Investigaciones de Historia de las Regiones Hispanoamericanas (GIHRA) y profesor en la Maestría en Historia de la Universidad de Los Andes, Mérida, Venezuela; investigador especial invitado en la Universidad Nacional Experimental Rafael María Baralt; miembro del Programa de Estímulo a la Investigación nivel B; Premio Nacional de Ciencia y Tecnología, mención Ciencias Sociales, 2017. https://orcid. org/0000-000I-7014-8105. 
primera mitad del siglo xVIII, cuyos efectos impactaron tanto a sus respectivos valles como a su población, en eventos de impacto lento y súbito. Asimismo, se describe el proceso de adaptación y respuesta de dichas colectividades a esos terribles sucesos, o su resiliencia.
El estudio se realizó a partir de la recolección de información documental y cartográfica sobre los tópicos señalados. Además, se ubican y se describen las modificaciones en los sistemas hídricos, el sismo, el deslave y sus efectos, y se presentan figuras.

Palabras clave: vulnerabilidad, desastres, geohistoria, sur del lago de Maracaibo, inundaciones, terremotos, deslave, historia ambiental.

\section{$\begin{array}{llllllll}\mathbf{A} & \mathbf{B} & \mathbf{S} & \mathbf{T} & \mathbf{R} & \mathbf{A} & \mathbf{C} & \mathbf{T}\end{array}$}

The research focuses on describing and analyzing the changes in the riverbeds of the Torondoy, Castro or San Pedro and Mojaján or Culebra rivers, in the south of Lake Maracaibo (Venezuela), their periodic floods and the disaster caused by the seismic movements of 1673 and 1674, its aftermath, the subsequent landslide and successive overflows experienced during the seventeenth century and the first half of the eighteenth century whose effects impacted their respective valleys as their population, events that constitute slow and sudden impact. It also describes the process of adaptation and response of these communities to these terrible events, or their resilience. The study was carried out on the collection of documentary and cartographic information on the indicated topics, the modifications in the water systems, the earthquake, the landslide, and its effects and is presented in figures.

Keywords: vulnerability, disasters, geohistory, south of Lake Maracaibo, floods, earthquakes, landslide, environmental history.

\section{Introducción ${ }^{1}$}

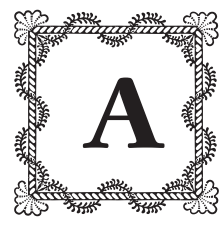

unque el sur del lago de Maracaibo (Venezuela) está conformado por doce valles, el presente estudio se centra en los de San Pedro, Bobures y Torondoy, irrigados por los ríos Torondoy, Castro o San Pedro y Mojaján o Culebra ${ }^{2}$. Estos valles se caracterizan por su extraordinaria productividad agrícola, debido a sus

I Artículo de investigación resultado del proyecto . $^{\circ} 2017000408$, financiado por el Ministerio del Poder Popular para la Educación Universitaria, Ciencia y Tecnología, Caracas, Venezuela.

2 Dichos valles se ubican en la cuenca del lago de Maracaibo, la cual comprende una extensa depresión costera que se dilata aproximadamente entre los $9^{\circ}$ y $12^{\circ} \mathrm{N}$ y los $70^{\circ}$ y $72^{\circ} \mathrm{O}$ (Espinoza). 
excepcionales condiciones de fertilidad y humedad, las cuales fueron aprovechadas por los hispano-criollos para desarrollar las haciendas productoras de cacao y otros cultivos de subsistencia, como lo describían los ediles de Maracaibo en I7i6:

[...] que lo principal de las haciendas del fruto de cacao que asisten en los valles de San Pedro y Santa María de esta jurisdicción [...] y el pan cotidiano con que se mantiene esta dicha ciudad y su jurisdicción se compone de maises, plátanos y casaves los que se conducían de las referidas haciendas [...] (AGNC, CO, 2, doc. I4, ff. 3 v.-5 r.)

Esa fertilidad se origina en su sistema hidrográfico, climático y orogénico, que también es razón de amenazas, vulnerabilidades y riesgos. Debido a ello, es necesario describir el comportamiento de los mencionados afluentes que escurren sobre esa llanura, caracterizados por los constantes cambios en la dirección de sus cursos. Tales cambios ocasionan periódicas inundaciones, como consecuencia de la elevada velocidad y el gran volumen de agua que los afluentes transportan desde sus cuencas hasta su desagüe. Además, existe la posibilidad de que ocurran sismos y, al conjugarse, esos fenómenos pueden originar desastres.

Los factores enunciados se consideran amenazas, definidas como el “[...] peligro latente que representa la probable manifestación de un fenómeno físico de origen natural, que se anticipa puede producir efectos adversos en las personas, la producción, la infraestructura, los bienes y servicios" (Lavell et al. 22). De acuerdo con su comportamiento, las amenazas son de impacto lento (sequías, epidemias, persistencia en algunas inundaciones) o súbito (temblores, erupciones volcánicas, inundaciones, maremotos, ciclones, granizadas o heladas) (Hercer y Di Virgilio I5-I6).

La diferencia fundamental entre los tipos de amenazas mencionados radica en que las de impacto súbito son fácilmente identificables, ya que su ocurrencia representa un momento coyuntural y afectan de manera catastrófica; por ello, tanto sus secuelas como la respuesta social a ellas son casi inmediatas. Por el contrario, las amenazas de impacto lento son producto de la acumulación, de la permanencia o de la ausencia prolongada de ciertos fenómenos, como el inusitado incremento o descenso de las precipitaciones, o bien una epidemia humana o animal. Aunque sus consecuencias se advierten a través del tiempo, se manifiestan después de semanas o meses, y pueden extenderse incluso por varios años o décadas (García I6). 
Cuando se identifican amenazas, es posible reconocer condiciones específicas presentes en una colectividad que pueden magnificar los eventuales daños que podrían ser causados por dichas amenazas. Se trata de los indicadores de riesgo físico, a través de los cuales se logra precisar el grado de vulnerabilidad de la comunidad. En consecuencia, la vulnerabilidad está representada por un manejo incorrecto de los recursos que distorsiona los ambientes locales y regionales (García 5-69).

En ese sentido, se han identificado distintos tipos de vulnerabilidad. Entre estos se encuentra la vulnerabilidad física, la cual se origina en la ubicación de "[...] los asentamientos humanos en zonas de riesgo y [...] las deficiencias de las estructuras físicas para absorber los efectos de esos riesgos” (Wilches 25). Por su parte, la vulnerabilidad económica es consecuencia de la carencia de recursos en los sectores deprimidos - los más expuestos a los efectos de un desastre, debido a su pobreza-, de la desigualdad, del inadecuado uso del suelo y de los recursos naturales, así como del sostenido crecimiento demográfico (Wilches 27).

A las anteriores vulnerabilidades se debe agregar la vulnerabilidad social. Esta depende del nivel de cohesión interna de una comunidad y se expresa en la carencia de vinculaciones entre sus miembros. Por lo tanto, se presenta cuando dichas vinculaciones son limitadas y deficientes, por la ausencia de sentido de pertenencia y del propósito de organización colectiva, debido a la inexistencia de formas de agrupación de la sociedad civil que posibiliten su cohesión con la finalidad de emprender acciones concretas en función de su autoprotección (Wilches 28-29).

Adicionalmente, la vulnerabilidad política se entiende como el nivel de autonomía de una comunidad para proceder a la toma de decisiones oportunas e inmediatas con el fin de resolver las situaciones que la afectan. Es decir, mientras mayor sea su capacidad de decidir de manera autónoma, menor será su vulnerabilidad política (Wilches 30). Otra forma de vulnerabilidad es la técnica, resultado de la incapacidad de aportar diseños y construir estructuras resistentes y efectivas que mitiguen los efectos de los riegos en zonas expuestas a ellos (Wilches 3I).

También existe la vulnerabilidad ideológica, que comprende la actitud y eventual respuesta que puede desplegar una comunidad ante una amenaza de desastre "natural", o ante su ocurrencia, la cual depende significativamente de la concepción de sus miembros sobre su entorno y sus recursos. En ese sentido, cuando en una colectividad prevalecen las concepciones místicas, según las cuales los desastres "naturales" son manifestaciones de la "voluntad 
de Dios”, en contra de las cuales los seres humanos están imposibilitados para actuar y, por lo tanto, "nada pueden hacer". Asimismo, cuando se cree en la inflexibilidad del destino, del cual es imposible escapar, y por tanto las únicas respuestas que es posible esperar serán el dolor, la pasividad y la resignación. Por el contrario, si en una colectividad prevalece la mentalidad que promociona la capacidad de la humanidad para la transformación del mundo y se identifican las causas naturales y sociales que conducen al desastre, la reacción de esta podrá ser más proactiva, más constructiva y de resistencia en contra de lo que parece inevitable (Wilches 32). De acuerdo con lo expuesto, es dado afirmar que los niveles de vulnerabilidad dependen del desarrollo socioeconómico, de las capacidades, de la disponibilidad y del manejo eficiente de los recursos. De hecho, es la misma colectividad la que los origina y acumula, conformando así una situación de riesgo.

En ese orden de ideas, es importante entender que cualquier evento natural constituye un riesgo para una sociedad cuando se desconoce su frecuencia, magnitud, forma de ocurrencia y periodos de manifestación. Por esas razones, se considera que el riesgo (o la probabilidad de ocurrencia del fenómeno) está ligado a la capacidad de predecir y ajustarse a un evento natural cíclico que amenaza a una determinada sociedad (Hercer y Di Virgilio 69). Por lo tanto, se debe enfatizar que la presencia del riesgo es resultado de la consideración del eventual

[...] daño, destrucción o pérdida esperada obtenida de la convolución de la probabilidad de ocurrencia de eventos peligrosos y de la vulnerabilidad de los elementos expuestos a tales amenazas, matemáticamente expresado como la probabilidad de exceder un nivel de consecuencias económicas y sociales, en un cierto sitio y en un cierto periodo de tiempo. (Cardona 6)

En consecuencia, la conjunción de esos fenómenos expuestos coadyuva en la contingencia de un desastre, que se presenta cuando

[...] un evento o suceso que ocurre, en la mayoría de los casos, en forma repentina e inesperada, causando sobre los elementos sometidos alteraciones intensas, representadas en la pérdida de vida y salud de la población, la destrucción o pérdida de los bienes y producción de una colectividad y/o dańos severos sobre el medio ambiente. Esta situación significa la desorganización de los patrones normales de vida, genera adversidad, desamparo y sufrimiento en las personas, efectos sobre la 
estructura socioeconómica de una región o un país y/o la modificación del medio ambiente; lo anterior determina la necesidad de asistencia y de intervención inmediata. (Cardona I-2)

Por lo tanto, para que ocurra un desastre solo es necesario que un evento natural, previsto o imprevisto, se interrelacione con una población, lo cual constituye "la actualización del grado de vulnerabilidad, en términos de manifestación abierta de un sistema social determinado" (Hercer y Di Virglio 69). Igualmente, cuando sobreviene un desastre, se considera que es la manifestación evidente e indiscutible de la imprevisión y la ausencia de soluciones a escenarios límites o amenazas preexistentes en un colectivo determinado.

La respuesta a la ocurrencia de los desastres es la resiliencia. Esta consiste "en la capacidad de un sistema de absorber una perturbación y reorganizarse, sufriendo cambios pero manteniendo esencialmente la misma función, estructura e identidad" (Ize I). En ese sentido, la resiliencia "para una sociedad puede significar la capacidad de manejar hechos tales como preocupaciones políticas y catástrofes naturales de una manera sostenible a largo plazo" (Ize i; Moberg 6).

De acuerdo con lo expuesto, reviste importancia fundamental el estudio del desastre ocurrido en el sur del lago de Maracaibo como resultado de los precursores $^{3}$ y del sismo de 1674 , evento que ofrece insospechadas posibilidades para explicar una serie de fenómenos en los que confluyen factores geográficos, demográficos, económicos, sociales y políticos que tuvieron catastróficos efectos sobre aquella colectividad. Lo anterior, debido a que se presentó la coincidencia de vulnerabilidades de impacto lento y eventos de impacto súbito, cuyas secuelas fueron notablemente devastadoras (Ramírez y Aranguren). Dichos eventos suelen motivar resiliencia ${ }^{4}$.

Este escrito se centra en identificar y caracterizar las diversas amenazas representadas por las modificaciones en el sistema hidrográfico de los ríos Torondoy, Castro o San Pedro y Mojaján o Culebra en el sur del lago de Maracaibo (Venezuela) durante los siglos XVII-Xvin. Las variaciones en el curso de los mencionados ríos ocasionaron periódicas inundaciones en sus respectivos valles, el momento coyuntural del desastre ocasionado por los movimientos telúricos

3 Se define como precursor a uno o varios eventos sísmicos de menor magnitud que preceden a un sismo propiamente dicho o de alta intensidad en la escala de Richter.

4 Sobre la resiliencia existen numerosos estudios que describen su importancia y significación en diferentes sociedades (Calvente; Daza; Folke; Folke et al.; Gallopin; Ize; Moberg; Twigg). 
de 1673-1674, así como el posterior deslaves de ese último año. Lo anterior permite entender y aprehender los procesos cíclicos recurrentes que pueden llegar a reproducirse en tiempos venideros.

Las variables del análisis están determinadas por los factores de amenaza, vulnerabilidad, riesgo y resiliencia. Los indicadores de dichas variables son: la red hidrográfica, los patrones climáticos y la conformación del relieve en los valles enunciados, lo cual determina el comportamiento de los afluentes. Este comportamiento pudo ser apreciado desde principios del siglo Xvir y se mantiene hasta la actualidad, caracterizado por periódicas inundaciones y reiteradas modificaciones en los cauces fluviales, con la presencia de dos episodios de extrema dificultad: el deslave de I674 y las riadas ocurridas entre 1748 y I758, las cuales ocasionaron numerosos daños.

Con el fin de explicar el comportamiento de las corrientes fluviales, se acude a fuentes cartográficas de los siglos XVII y XVIII, en particular los mapas de la laguna de Maracaibo y de los valles de Bobures, Castro, Cuéllar de la Isla y la sabana del Espíritu Santo ${ }^{6}$. A partir de tales mapas se elabora el análisis cartográfico-histórico, teniendo en cuenta un mapa base de los mencionados valles, ubicado en Google Earth, utilizando la imagen de satélite ven_shade_9om.tif. Sobre este mapa se muestran los cambios experimentados por la red hidrográfica durante el periodo estudiado y sus secuelas. De manera complementaria, se hace una detenida revisión de la información proporcionada por documentos que reposan en diferentes legajos en el Archivo General del Estado Mérida (AGEM), en el Archivo Arquidiocesano de Mérida (алм), en el Archivo General de Indias (AGI) y en el Archivo General de la Nación Colombiana (AGNC), a efectos de conocer y explicar su impacto geohistórico durante el periodo estudiado.

5 Un deslave es un deslizamiento o derrumbe de tierra, un desastre relacionado con las avalanchas, pero en lugar de nieve lleva tierra, rocas, árboles y casas, entre otros. Los deslizamientos de tierra pueden ser provocados por terremotos, erupciones volcánicas o inestabilidad en las zonas circundantes, así como explosiones causadas por el hombre para construcciones. Los corrimientos de barro o lodo son un tipo especial de deslave cuyo causante es el agua que penetra en el terreno debido a lluvias fuertes, lo modifica y provoca el deslizamiento.

6 El análisis se realiza comparativamente sobre los siguientes mapas: "Laguna de Maracaybo. 1642-2-5" (AGI, MPV, 3B, p. 57); "Carta corográfica de la laguna de Maracaibo, donde se demuestran laz entradas de loz, sitios y fuerzas de las ciudades, lugares y puertos de lagunillas demostrado por escala de a, b y c" (AGI, MPV, 57, 1682, 22, 2); “Descripción de la laguna de Maracaibo, sacada por escala plana y petipie de leguas castellanas, con las ciudades, pueblos, balles, puertos y castillos que encierran en si por ABC" (AGI, MPV, 286); "Mapa elaborado por Pedro Josep Antúnez Pacheco" 1760 (AGNC, M 4, n. ${ }^{\circ}$ 386-A) y el "Mapa elaborado de por Fray Fernando Mayorga en I76I" (AGNC, M 4, n. ${ }^{\circ}$ 388-A). 
De esa forma, se superan las inexactitudes técnicas que presentan los registros cartográficos elaborados durante el periodo colonial, tales como la carencia de precisión astronómica, fallos de escala, modificaciones en la toponimia y deficiencias relativas al nivel de detalle del mapa. Debido a estas limitaciones se acude al examen de la información registral, lo que permite establecer aproximadamente la compresión de los cambios fisiográficos apreciables en el espacio estudiado (Roa), en particular las modificaciones experimentadas en los cursos de los afluentes que se presentan en las figuras con carácter de aproximaciones?.

La investigación se inscribe en la corriente de geografía histórica. El estudio se presenta en seis partes, las cuales describen las características fisiográficas ${ }^{8}$ de los valles en estudio, la ocurrencia de los precursores y el sismo de I673-I674, los efectos de estos, la ocurrencia del deslave y sus secuelas, las modificaciones y las consecuencias del comportamiento de los afluentes, y, finalmente, se expone el proceso de resiliencia.

\section{Características fisiográficas del sur del lago de Maracaibo}

Los valles irrigados por los ríos Castro, Torondoy, Mojaján o Culebra y Muyapá se caracterizan por sus elevados índices de pluviosidad, razón por la cual dichos afluentes fluyen con ingentes niveles de agua desde las cuencas altas que escurren sobre el $90 \%$ de las planicies. Tal característica es el resultado de la situación geográfica, debido a que esa explanada se ubica en el sur de la cuenca en cuyo centro está su principal colector, el lago de Maracaibo. Asimismo, es preciso señalar que los mencionados acuíferos arrastran desde sus torrenteras elevadas cantidades de humus que se depositan en el suelo, dotándolo de una gran fertilidad debido a sus componentes biodegradables. Esa fertilidad determinó el crecimiento de la selva tropical, entre cuyas variedades vegetales se halló el cacao (Ramírez, "El cultivo" 69). Esas favorables condiciones edáficas motivaron a los

7 Deseo expresar mi reconocimiento al ingeniero geólogo Reina Aranguren Becerra, quien realizó los mapas que se presentan en este artículo.

8 Visión general de las formas del relieve, identificadas y definidas a partir del análisis integral de la información topográfica, geológica, hidrológica y edafológica, para formar unidades relativamente homogéneas que representan las diferentes provincias y subprovincias en las que se ha dividido el país. 
hispano-criollos a expandir la frontera agrícola y se inició así la modificación de sus paisajes culturales (Teixeira IO9-II4) durante los siglos XVI y XVII.

En aquel entonces se ignoraban las particularidades geológicas, edáficas y freáticas de esa llanura, pero al avanzar el proceso de expansión de los sembradíos quedó al descubierto una dura y frustrante realidad: las frecuentes inundaciones de los afluentes, al mismo tiempo que irrigaban y fertilizaban el suelo, anegaban las arboledas de cacao, debido a lo cual se perdía el esfuerzo empleado en su conformación. Esta situación fue descrita por sus propietarios con expresiones como: "se la llevó el río" y los hizo considerar que las tierras eran "ynutiles y anegadizas".

Esos indeseables efectos experimentados durante el siglo XVII fueron las inmediatas consecuencias del comportamiento de la red hidrográfica y de los patrones de desagüe prevalecientes en los ríos Muyapá, Torondoy, Castro o San Pedro y Mojaján o Culebra, los cuales a su vez fueron el resultado de su conformación morfológica, de la variación y la dinámica pluviométrica, del estado y la situación del régimen de ocupación, de las condiciones ecológicas de los diferentes sistemas ambientales y de su explotación agrícola.

En ese sentido, es preciso explicar que la planicie sur del lago de Maracaibo se encuentra en los bordes de un profundo hundimiento, donde está el lecho del mismo lago, lo cual determina la estructura de la red hidrográfica en los valles en estudio. Dicha estructura se caracteriza por corrientes fluviales cuyas fuentes se ubican en las cumbres andinas y escurren sobre sus flancos exteriores formados por vertientes abruptas, largas y rectilíneas, con inclinaciones superiores al $40 \%$. Estas vertientes abren profundos surcos en las laderas, cuyo perfil orográfico presenta colinas bajas disectada $\mathrm{s}^{\mathrm{10}}$ e individualizadas, frecuentemente redondeadas o alargadas, y pendientes pronunciadas que se inclinan desde alturas que superan los $4.000 \mathrm{~m} \mathrm{s.} \mathrm{n.} \mathrm{m.} \mathrm{y} \mathrm{descienden} \mathrm{hasta} \mathrm{llegar}$ a la planicie lacustre situada a o m s. n. m. (Goldstein et al. 216). Esto explica

9 Francisca de Vergara sostenía que a su estancia "se la llevó el río" (AGI, EC, leg. 836-c., f. 82 r.-v.). Los agustinos de Gibraltar declararon que sus tierras en San Pedro eran "inútiles de montañas y anegadizos y las de sabanas asimismo eriazas de poco o de ningún aprovechamiento” (AGI, EC, leg. 836-c., ff. I7I v.-I72 r.). Don Pedro de Silva declaraba que sus tierras "eran anegadizos por no haber tierra útil” (AGI, EC, leg. 836-c, f. 174 r.-v.). Don Fernando de Valderrama recibió tres estancias, contiguas al río Torondoy, pero solo compuso dos porque la tercera se "la anegó el río" (AGI, EC, leg. 836-c, ff. 178 v.-I79 r.).

Io Es un tipo de suelo que tiene cárcavas o agrietamientos en forma ramificada debido a la erosión de tipo hídrico. 
la elevada velocidad con que se deslizan las aguas, como se refirió en I76r al describir el río Torondoy como: “[...] uno de los más crecidos que le dentrán a esta laguna y entre todos ellos el más violento porque biene muy despeñado de la serranía" (AGNC, CO, 2, doc. I4, ff. 466 v.-467 r.).

Finalmente, esos acuíferos fluyen en las llanuras, donde se ensanchan y forman abanicos aluviales ${ }^{\text {II }}$, debido a que los suelos arenosos inmediatos al litoral impiden su desagüe en el lago de Maracaibo, como consecuencia de su gran capacidad de absorción del líquido. Ese fenómeno origina ciénagas y meandros, como reza un testimonio de I76r: "[...] que siendo la tierra de aquellos territorios arenisca, por qualquiera parte las aguas derramadas de los dichos ríos hacen curso con facilidad y se encajona lo más del río [...]" (AGNC, CO, 2, doc. I4, f. 227 r.).

Los ríos mencionados son asimismo colectores de elevadas precipitaciones, lo cual tiene significativa importancia e influencia en los procesos morfodinámico y de arrastre de estos ${ }^{12}$. Dichas precipitaciones son consecuencia de factores climatológicos que se derivan de la ubicación del arco montañoso que se encuentra al sur de la depresión del lago de Maracaibo. Igualmente, se deben a la evaporación que experimentan las aguas de este lago, la cual a su vez es resultado de la circulación de vientos cargados de humedad sobre las montañas que lo rodean. Estos vientos determinan la baja presión y hacen que la masa de aire caliente ascienda y, por efectos de convección, origina corrientes de aire que se proyectan sobre las laderas de las montañas y se condensan en fuertes y constantes lluvias. Por las razones expuestas, los índices de pluviosidad no son uniformes en el espacio estudiado; en algunos casos "predominan las precipitaciones que superan los $2.500 \mathrm{~mm}$ anuales, a diferencia de los sectores del suroeste, cuyo promedio anual se sitúa entre los I.400 mm y los I.80o mm. Esta distribución espacial de las lluvias motiva que las cuencas altas o medias y el bosque húmedo tropical reciban entre $1.600 \mathrm{~mm}$ y $2.700 \mathrm{~mm}$ de precipitación anual" (Espinosa 83-84).

II Un abanico aluvial o cono de deyección es en geomorfología una forma del terreno o accidente geográfico que se presenta cuando una corriente de agua que fluye rápidamente entra en una zona más tendida y su velocidad disminuye, debido a lo cual su cauce se extiende en forma de abanico, en general a la salida de un cañón hacia una llanura plana.

I2 "[... y que las aguas del río Torondoy se distinguen entre todas por ser del color blanco como se disse y las máss eladas de todas ellas y olor a mene que este solamente lo tiene" (AGNC, CO, 2, doc. I4., ff. 466 v. -467 r.). 
Los elevados niveles de pluviosidad a los que se ha hecho referencia determinan que los ríos incrementen sus caudales y se deslicen torrentosos, a gran velocidad, hacia la planicie lacustre. Esa situación fue observada de forma recurrente desde la primera mitad del siglo XviI, en especial en el decurso del río Torondoy, considerado el más caudaloso del área ${ }^{13}$. Como consecuencia de las frecuentes crecidas, en numerosas oportunidades se modificó la dirección de su cauce y sus aguas se dirigieron a los canales de otros acuíferos. Esto también ocurrió con los ríos Castro o San Pedro y Muyapá. Alternativamente, tanto el Castro como el Torondoy dirigieron sus aguas hasta el cauce del Muyapá ${ }^{14}$.

En ese sentido, es preciso explicar que durante la primera mitad del siglo XVII el río Torondoy circulaba en sentido sur-norte desde su ingreso a la planicie lacustre, aproximadamente en el sitio donde hoy está situada la población de Caja Seca, en forma casi rectilínea hasta su desembocadura, la que entonces se ubicaba inmediata al actual poblado de Bobures, específicamente en el puerto de Alaña o Puerto Hondo (véase figura i). En dicho espacio se expandía y formaba un abanico aluvial cuyas corrientes inundaban las haciendas ubicadas en sus márgenes, como la perteneciente a Pedro Hernández de Galarza, que en I715 la donó a los jesuitas de Mérida, sembrada con iı.ooo árboles de cacao. Los padres, sin embargo, sufrieron los efectos devastadores de las riadas del Torondoy y se lamentaban por las pérdidas ocasionadas, debido a que las inundaciones conllevaban los persistentes "[...] robos que todos los años hacía el río Torondoy [...]”. Por tal razón, se habían perdido más de 3.000 árboles en el lapso de apenas dos años, ya que en I7I8 escasamente había 8.000 árboles de cacao (Febres I28-I30) (figura I).

Las incesantes riadas constituyeron una amenaza de carácter lento. Por ello, es necesario explicar que los desastres son el resultado de procesos que generan crisis durante la ocurrencia de una amenaza, la cual se transforma en

13 “[... que es verdad que el río Torondoy es uno de los más caudalosos que componen esta laguna por venir más precipitado, porque la serranía donde el nace es la más encumbrada de la sirculan en esta laguna" (AGNC, CO, 2. f. 407 r.). Véase el mapa de I76I (AGNC, $M 4$, n. ${ }^{\circ} 388$-A).

I4 Se señalaba que "por vajo de la savana en que está poblado el capitán Francisco Ortiz, de un lado, y de otro del caño que va por allí que es el que sale de Torondoy y entra en el río de Castro" (BNBFC, $C M T$, caja II, doc. I, f. I8I r.-v.). Esa posesión se expandía "desde la quebrada de Muyapá hasta el río de Castro [...]" (AGEM, $P$, t. IX, ff. 76 r.-82 v.). Posteriormente, en 1650 , se describe una estancia ubicada en Bobures, en frente de un "caño seco que por tiempos trae agua del río de Torondoy y baja por las labores de dicha doña María de Cuéllar y Doña Isabel Cerrada y lo largo de la dicha estancia hacia el río de Castro" (AGI, EC, leg. 836-c, f. I70 r.-I7I v.). 


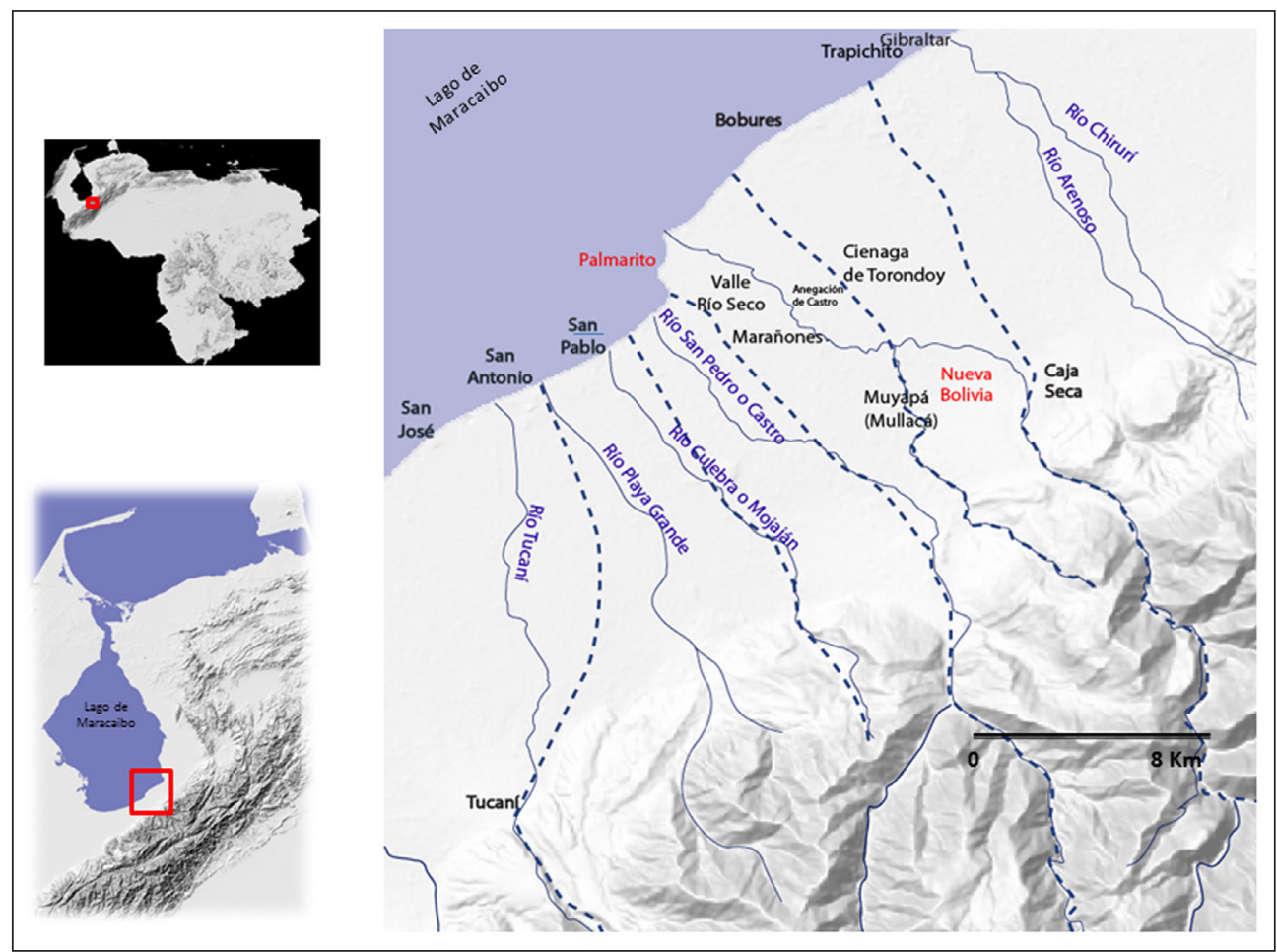

$\rightarrow$ FIGURA I .

Recorrido de los ríos Torondoy, Castro o San Pedro y Mojaján I620-I680 Cursos antiguos en líneas punteadas, cursos actuales en líneas continuas.

Fuente: elaboración propia con base en AGEM, P, tt. I-C; Mtrs, tt. I-XXX; AGI, MPV, 3B, I642, 2-5.

detonador o revelador de situaciones críticas preexistentes. Estas últimas se hacen especialmente visibles para las sociedades en determinados momentos históricos. Así ocurrió en el sur del lago de Maracaibo a finales de 1673 y principios de i674, cuando un sismo reveló la vulnerabilidad existente en aquella planicie, vulnerabilidad que apenas había sido percibida por esa sociedad agraria.

\section{Los precursores y el sismo de 1674}

La insospechada magnitud en la coincidencia de eventos geológicos y climáticos combinados con los sísmicos se hizo presente como consecuencia de los precursores sucedidos en 1673 , el terremoto y el posterior deslave en 1674 , que afectaron el perfil del suelo y los sistemas de desagüe en los valles que surcan 
los ríos Torondoy y San Pedro. Esa grave situación se inició repentinamente, el 8 de diciembre de 1673 , a eso de las cuatro de la madrugada (Palme y Altez 2), cuando la tierra se estremeció "con los horrorosos temblores"15.

Los techos de paja se desplomaron y en su colapso ocasionaron la muerte de personas sobre las cuales cayeron. En este precursor, numerosas edificaciones del puerto de Gibraltar colapsaron. Posteriormente, en enero del siguiente año, I674, la tierra volvió a sacudirse, lo cual causó el pánico de los pobladores debido a "tantos temblores de tierra aunque permitió fueron dos bien horrorosos, el uno a los doce de enero viernes en la noche y el otro a los diez y seis del dicho mes, a las tres de la tarde" (AGNC, $M M$, t. I37, ff. 698 r.-v.). Esos movimientos telúricos estremecieron a parte del contorno de la laguna y se sintieron en los doce valles del sur del lago. Asimismo, el terremoto arrasó y destruyó las ciudades de Mérida, Barinas y Trujillo, y se vieron afectados algunos edificios en el Tocuyo (Palme y Altez 2).

En San Antonio de Gibraltar continuó temblando durante los siguientes siete meses, como se desprende del testimonio de Juan de Sevilla Guerrero, quien señaló en septiembre:

[...] que en diez y seis del mes de henero de este presente ańo de setenta y quatro día martes por la tarde entre los rigurosos temblores y terremotos de tierra que Dios nuestro señor fue servido de ynviarnos y por nuestros pecados fue uno de los más recios y horrorosos este dicho día además de los antecedentes que hubo y han continuado hasta el día de oy. (AGNC, Mis, t. I49, ff. 78 r.)

Para escapar de la desolación, la destrucción y la muerte, los pobladores abandonaron el puerto, temiendo nuevos e inminentes desastres. Creyeron estar a salvo en las haciendas, pero contrariamente a lo que imaginaban, tales previsiones no los protegerían de una tragedia aún mayor que habría de suceder ${ }^{16}$.

I5 "[...] luego en el año de setenta y quatro con los horrorosos temblores que se padecieron con aniquilación de edificios y templos y casas de esta ciudad [Mérida] que oy están desiertas e inhabitables" (AGI, $S D$, leg. 202, f. 64 r.).

I6 "[... les ha obligado a retirarse a los campos sin venir a la ciudad así por no tener casa en ella para su abitación como por la desnudes que padecen” (AGI, $S D$, leg. 202, f. 47 v.). 


\section{Los efectos de los precursores y el sismo de 1674}

Aunque es muy difícil describir los efectos de los precursores de 1673 y del sismo de 1674 , debido a que la información documental es fragmentaria, se pueden hacer no obstante algunas precisiones. En primer lugar, se aprecia que el espacio urbano, localizado en la villa de Gibraltar, tuvo significativos daños. Aunque se describen edificaciones con dos pisos en el interior del poblado, se considera que la mayoría de los inmuebles estaban construidos con materiales frágiles que tuvieron poca resistencia ante la intensidad de los sismos. Entre esos materiales de construcción estaban paredes de bahareque, probablemente con pisos y entrepisos de madera, y techadas las más de las veces con paja. Por lo tanto, se desplomaron con rapidez ${ }^{17}$. Aun la iglesia parroquial y también el templo del convento de San Agustín se presume que se derrumbaron durante el terremoto, porque en 1675 se menciona que todo el convento estaba "en ruinas" (Campo I66). En tal virtud, el puerto sufrió una destrucción casi total, si se tiene en cuenta que los movimientos fueron de elevada magnitud, como lo sugiere Palme en su estudio, quien los califica en un grado de intensidad vir y hasta viII en la escala $\mathrm{MKS}^{18}$ (Palme y Altez 2). Sin embargo, la mayor parte de los deterioros causados en el espacio rural ocurrió como consecuencia del posterior deslave.

El deslave tuvo como causa dos eventos coincidentes con los sismos. El primero fueron los elevados niveles de pluviosidad, por lo cual es preciso explicar el régimen anual o patrón de lluvias ${ }^{19}$, cuyos máximos índices ocurren en octubre y mayo, en tanto que sus mínimos se presentan en febrero y julio-agosto. En algunas zonas del sur de la cuenca se observa la inversión de los máximos,

I7 “[...] aunque el puerto de Gibraltar por no tener casas de texa no tubo pérdida de edificios [...]" (AGNC, $M M$, t. 137 , f. 698 r.-v.).

I8 Medvédev-Sponheuer-Kárník, también conocida como MSK o MSK-64, es una escala de intensidad macrosísmica usada para evaluar la fuerza de los movimientos de tierra, con base en los efectos destructivos en las construcciones humanas y en el cambio de aspecto del terreno, así como en el grado de afectación entre la población. Tiene doce grados de intensidad, el más bajo de los cuales es el número I, que se expresan en números romanos para evitar el uso de decimales. Propuesta en 1964 por Serguéi Medvédev (Unión Soviética), Wilhelm Sponheuer (República Democrática Alemana) y Vít Kárník (Checoslovaquia), se basa en los datos disponibles a principios de los años sesenta, obtenidos mediante la aplicación de la escala Mercalli modificada y también por medio de la aplicación de la versión de I953 de la escala de Medvédev, conocida como la escala de intensidad sísmica de Geofian.

I9 Estación o temporada de lluvias. 
es decir, el máximo principal ocurre entre mayo-junio, mientras que el máximo secundario se presenta en octubre (Espinoza 78).

El segundo factor estuvo representado por el desplazamiento de rocas y sedimentos, como secuela del sismo, que se depositaron en las cuencas de los ríos, en particular en las orillas de las torrenteras, donde se han profundizado los cauces de los ríos desde las escarpadas montañas hasta las llanuras. Allí se abatieron sedimentos rocosos y vegetales y se formaron represamientos que impidieron la circulación de las corrientes ${ }^{20}$ : "[...] que el firmamento de los riscos, peńascos y serros los movieron de una parte a otra en casi todo su distrito abriendo profundas grietas a la tierra y atajando los ríos caudalosos [...]"21.

\section{El deslave de 1674 y sus efectos}

Las lluvias se incrementaron y las aguas se depositaban en las lagunas de obturación formadas por los represamientos situados en los cursos superiores de los afluentes que vierten sus aguas en el lago de Maracaibo ${ }^{22}$. Al mismo tiempo, la población se hallaba aposentada fuera del puerto, donde se aprestaba a la recolección del cacao destinado al comercio en las venideras ferias.

Aquella fatídica mañana todo comenzó con una suave llovizna que en el trascurso del día se convirtió en un diluvio. Al atardecer, en los valles de Cuéllar de la Isla, Mojaján, Castro y Espíritu Santo se escuchó un lejano rumor que venía de la serranía. Se pensó que era otra réplica del sismo, pero no tembló. Entonces, fue "servido Dios Nuestro Señor" ${ }^{23}$ que un alud de barro, fango, rocas y una ola de agua se deslizaran desde la serranía y cubrieran planicies, arrastrando las arboledas de cacao, cuyas raíces carecían de la estabilidad suficiente debido a que el suelo se había estremecido como consecuencia de los sismos y las había sumergido en una capa de sedimentos que se elevó por encima de tres metros de altura. Como entonces se describió:

20 "[...] y habiéndose removido y desmoronado los montes y echo represas" (AGI, $S D$, leg. 202, f. 47 v.).

21 "[...] y no solo arassaron los edificios [...]" (AGI, $S D$, leg. 202, f. 92 v.).

22 "[...] las grandes anegaciones que hicieron los ríos se llenaron y anegaron las estancias de cacao en la ciudad de Xibraltar y en los llanos de Chama sin quedar ninguna esenta de esta desdicha" (AGI, $S D$, leg. 202 , f. 57 r.-v.).

23 Isabel Ana de Rivas, al decir que: "fue servido Dios Nuestro Señor que entrase el río Torondoy en ella y totalmente se la llevó” (AGEM, P, t. XXXVI, ff. 97 r.-II6 v.). 
[...] a causa de aberse desvolcanado los serros con dichos temblores dentro de ellos de que resultaron muchas y grandes avenidas de varro que inundaron la mayor parte de dichas hasiendas de lo más bajo hasta el cojogollo quedando estos y las casas de vivienda de dichas hasiendas enterradas y sumergidas $\left[\ldots . .{ }^{24}\right.$

De ese modo, los acuíferos se desbordaron, formaron avenidas entre las arboledas de cacao y los aposentos y, a su paso, sepultaron a los animales, a los esclavos, a sus propietarios. Todo quedó enterrado debajo de aquel fatídico deslave.

La magnitud del desastre fue tan excepcional que nadie podía reconocer los lugares donde estaban sus haciendas; el suelo estaba desierto como la playa del lago; ni siquiera las copas de los árboles más altos sobresalían del barro y fango que las cubrían. Nada fue reconocible,

[...] porque con los muchos serros que se cayeron y desmoronaron sobre los ríos y represas que hizieron, éstos salieron de madre y con abenidas de barro anegaron todas las haziendas de cacao y quedaron sumergidos todos los árboles de dicho cacao y casas de todas y las dichas haziendas en tal manera que todo quedó hecho plaia, sin que ningún dueño de dichas haciendas pasado después por los territorios supiera con individualidad en donde eran los parajes de dichas haziendas. (AGI, $S D$, leg. 202, f. 67 r.-v.)

La población pereció, enterrada viva o arrastrada por las corrientes hacia el lago, porque se hallaba en las estancias huyendo de los temblores y recogiendo las $\operatorname{cosechas}^{25}$. Todo aquel espacio arado, cultivado y edificado a lo largo de más de un siglo, formado por una sociedad agraria, desapareció en menos de seis meses. Ello se debió a las secuelas destructivas del deslave, las cuales tuvieron dos efectos. El primero consistió en que en una ancha faja de piedemonte no inundable se apreciaron fracturas en el suelo ${ }^{26}$, donde el barro cubrió las plantaciones de cacao, lo cual originó que se esterilizaran las arboledas ${ }^{27}$. En otros espacios, los taludes se derrumbaron debido a que el suelo en el que las arboledas asientan

24 “[... tenían hasiendas de arboledas de cacao, las cuales saben de público y notorio se perdieron en el todo con las crecientes de los ríos que ay en aquella jurisdicción” (AGI, $S D$, leg. 202, f. 6 v.).

25 "[...] que después de los dichos temblores se an muerto muchos esclavos" (AGI, SD, leg. 202, f. 16 r.).

26 "[...] y otras quedaron por las grandes grietas de la tierra maltratada sin remedio e infructuosas" (AGEM, $D H$, f. I2 v.).

27 “[...] por los parajes más altos les vañó dicho barro con lo cual se secaron lo restante de dichas arboledas" (AGI, SD, leg. 202, f. 6 v.). 
sus radicales estaba saturado con depósitos de humedad. Por esa razón, las arboledas que aún permanecían en pie hundían sus raíces en suelos arenosos, ya de por sí blandos. Como consecuencia de los movimientos sísmicos, las tierras fueron desmoronándose o fraccionándose con mayor intensidad, por lo cual se debilitó severamente la estabilidad de la capa vegetal, lo que a su vez hizo que esos árboles se abatieran y "fueran arrancados de raíss"28.

En las llanuras, las elevadas precipitaciones incidieron directamente en las condiciones del drenaje. Así, propiciaron su obstrucción en la franja inmediata al litoral y dieron lugar a áreas deprimidas y obstaculizadas en su escorrentía natural, las cuales quedaron anegadas por largo tiempo. Debido a esos factores y como consecuencia de la obstrucción de los cauces y el desbordamiento de los ríos Torondoy, Castro o San Pedro, Muyapá y Mojaján o Culebra, las planicies se empantanaron, lo que originó zonas cenagosas, especialmente en sus márgenes, porque allí las aguas fluyen con mayor caudal y velocidad durante el periodo de lluvias, y al llegar a la llanura se expanden, forman abanicos aluviales e inundan las sabanas. Estas, cuando se presentaron los eventos a los que se ha hecho referencia, fueron llamadas "avenidas" de los ríos ${ }^{29}$.

Por los factores mencionados, las explanadas se vieron severamente afectadas durante el deslave, como se refiere en el valle de Cuéllar de la Isla, donde la hacienda de doña Isabel Ana de Rivas fue totalmente anegada $a^{30}$, al igual que en la sabana del Espíritu Santo ${ }^{31}$, donde la estancia de María de Valdemoro sufrió la

28 “[... padeció en la de Gibraltar la total pérdida de muchas haciendas que en el todo se perdieron, porque las arboledas enteras se arrancaron de raíss" (AGEM, $D H$, f. I2 v.).

29 "[...] que el daño que reziben las haciendas de Río Seco es del río de Torondoy, porque éste dejando su caja atravesó la tierra a buscar la caja del río Muiacá y como este no tiene caja por no ser aquel su cauce biene el agua tendida por aquellas montañas donde a ymanado formarse esta laguna o siénaga sobre las cabeceras de las haciendas del valle de Río Seco, tan grande que no la alcanza con la vista a ver su fin y que las aguas de está ciénaga y las que se derraman en la caxa del Moiacá por no ser suficiente para resistir tanta abundancia son las que tienen anegadas a las haciendas de dicho valle y le amenazan de una total ruina si con el tiempo no se le pone reparo" (AGNC, CO, 2, doc. 14 , ff. 466 v.-467 r.).

30 " "... me dieron una estancia de árboles de cacao en la jurisdicción de San Antonio de Gibraltar, en el citio de La Isla, con nueve piezas de esclavos, en trese mil quinientos pesos más o menos y habiéndola trabajado y adelantándola mucho mi marido fue servido Dios Nuestro Señor que entrase el río Torondoy en ella y totalmente se la llevó toda y los dichos nueve esclavos por ser muy viejos se murieron" (AGEM, $P$, t. XXXVI, ff. 97 r.-116 v.).

$3 \mathbf{I}$ "[...] y dieron noticia que todas las estancias que había en el valle de la Sabana con las inundaciones de los ríos y el varro tan grande que llevaba desbaratado de los serros que habían caydo destruyeron todas las estancias del valle de la Sabana" (AGI, $S D$, leg. 202, f. 9 r.-v.). 
inundación del río Torondoy y quedó completamente perdida, yerma y sus dueños muy damnificados (agem, $P$, t. Xxx. ff. 234 r.-236 v.). Entre tanto, en el valle de Castro, la próspera hacienda de dońa Magdalena Ximeno de Bohórquez, que tenía Io.0oo árboles de cacao, despareció in totum (AGEM, $P$, t. Xxx. ff. I86 r.-I89 r.) cuando el río Castro la arrasó por completo (véase figura 3).

\section{Las inundaciones de finales del siglo XVII y la primera mitad del XVIII}

Es probable que otra de las secuelas del deslave haya sido la modificación de los perfiles en la superficie del suelo, producto del arrastre y la sedimentación del material transportado por los ríos, que se elevó exponencialmente, o también por el continuo acarreo de sedimentos que transportan las corrientes. Ambos eventos pudieron ser coincidentes y no excluyentes, así como haber originado desniveles en los surcos fluviales y reducir la profundidad de sus canales, obstruyéndolos, y por consiguiente su capacidad para el transporte de agua (AGI, $S D$, leg. 202, f. 6 v.). Así ocurrió con los ríos Torondoy, Castro o San Pedro y Mojaján o Culebra. Como consecuencia de ese fenómeno, esas corrientes fluviales "perdieron" sus "caxas", ocasionaron la modificación de sus cursos, produjeron la formación de ciénagas y pantanos, inundaron las haciendas cacaoteras ${ }^{32} \mathrm{y}$, por ende, provocaron la modificación abrupta en la dirección de sus cauces.

Ese fenómeno fue evidente entre I674 y i682, periodo en el cual se modificó la trayectoria del río Torondoy, tal vez debido a una obstrucción en su cauce producto a su vez del proceso de sedimentación, en sentido noroccidental. Esto creó un pronunciado meandro que dividió la corriente de su "madre vieja” y bifurcó las aguas del río, las cuales discurrieron sobre dos canales. El primero de estos siguió el antiguo curso y el segundo se dirigió al occidente. El segundo canal del río Torondoy se dirigió hasta el cauce del río Muyapá. Esta primera modificación hizo que el mayor volumen de aguas fuera conducido hacia las zonas circundantes al oeste de Bobures, donde inundó los terrazgos

32 "[... y las que no padecieron tanto que ha ido perdiéndose con las inundaciones de los ríos, que por ser toda tierra llana y mobediza a cualquiera creciente rompen y entran por las haciendas llebándose las arboledas y dejando esterilizada la tierra por las abenidas de la arena que dejan y assí tantas haciendas sólo han quedado las de los Padres de la Compañía y religión de Santa Clara y dos o tres haziendas de los vecinos" (AGEM, $D H$, f. I2 v.). 
adyacentes, dio lugar a la formación de ciénagas y significó la pérdida total de las haciendas del valle ${ }^{33}$. Como se ha expuesto, esa situación se había advertido desde i628, como lo testimonió Alonso Pacheco y Maldonado, al decir que sus estancias se ubicaban "abajo del Palmar y caño que viene del capitán Sebastián de Rosales [quebrada de Muyapá], caño que sale del río de Torondoy, lindando con estancias de él y Sebastián Rangel, corriendo hacia el río de Castro y los Bobures" (AGEM, $P$, t. XI, f. 320 r.-v.) (figura 2).

La división de las aguas del río Torondoy, circulando por esos cauces, se repitió cíclicamente, en periodos alternativos que se dilataban de veinte a treinta años, como lo mencionó Juan Antonio Rivas al describir una inundación ocurrida hacia 1720. Rivas explicó que, después de cierto tiempo, los ríos Torondoy y Castro retornaron a sus madres "viejas", y por esa razón al valle inmediato a Bobures se le conoció con el nombre de Río Seco ${ }^{34}$. De esa forma, a finales del siglo Xvir las aguas del río Torondoy se bifurcaban y discurrían tanto por su "madre vieja" como por su nuevo cauce, y al llegar al litoral sus corrientes se expandían desde las inmediaciones de Bobures bajos hasta la punta de San Pablo. Y en esa extensión tenía

[...] diferentes bocas y salidas y que no solamente por la tierra alta, sino por la baja, la tiene el dicho río toda cruzada y hecha sanjones sin que se discurra lugar por donde este no haya corrido y perdido copiosas haciendas en toda esta jurisdicción. (AGNC CO, 2, doc. I4, f. 463 r.) (figura 2).

Esa realidad continuó a principios del siglo XviII, después de la reocupación de las zonas afectadas, en especial en el valle de Bobures que experimentó un crecimiento sostenido de sus haciendas, a pesar de que se mantuvo la amenaza causada por las periódicas inundaciones decenales que ocurrieron en

“[...] es que por el año quarenta y cinco asistió en la hacienda del señor vicario don Pedro Joseph Antúnez, y que en ese entonces conoció inundada la hacienda que llaman Marañón de dicho Sr. Dr. y que oy es del señor alcalde don Thomás García y mucha agua tendida en todas las cabeceras de Río Seco y que todas ellas se encaminaban a las dos haciendas dichas y por la tierra más baja corrían hasta impedir con sus inundaciones el camino de la hacienda de los RP de la Compañía de Jesús nombrada Marañones, dejando perdidas en el todas la haciendas de Arenas y Gregorio Torres; y que estás aguas eran del río Torondoy que rompió su caxa y atravesó por sobre los ríos secos en demanda del río Muyacá que sale a la punta de San Pablo" (AGNC, CO, 2, f. 450 v.).

34 " “...] y que por esta razón con el discurso del tiempo que volvieron los ríos a sus madres volvió a quedar la tierra enjuta y comenzaron a fundar nuevas haciendas, y que por este motivo apellidan a aquel partido Río Seco" (AGNC, CO, 2, doc. I 4, f. 449 r.). 
I72I, $1739^{35}$ y especialmente entre 1748 y $1758^{36}$, cuando nuevamente las aguas del río Torondoy se desviaron hacia la "madre natural" del río Muyapá. Como resultado de ese fenómeno, las corrientes de los ríos Torondoy y Castro escurrieron únicamente por el cauce del Muyapá, cuyas riadas se dirigieron hacia los Bobures altos y los Ancones, causaron inundaciones y ciénagas y formaron una laguna ${ }^{37}$ (figura 3).

Adicionalmente, es preciso explicar que el río Castro también anegaba las zonas inmediatas al valle de Bobures, que se extendían hasta el Palmar (Palmarito), donde también se habían conformado haciendas. Periódicamente, esas

35 " [...] en el monte dieron con grandes anegaciones de aguas. Y que esta agua por la parte que mira al norte se descolgaba hasta una labor de platanal que llamaban por entonces Villalobos [...] cuya hacienda llaman Marañones, y que varias veces [...] vio el agua dentro de la arboleda, y no pasándose mucho tiempo puso el agua la tierra de costado de la referida hacienda, ynútil y siendo apoyo simple de la razón que expresa, averle suplicado a don Nicolás Joseph de Antúnez, [...] en uno de los años que median desde el año de treinta y nueve hasta el de quarenta y cinco le acompañara en el monte que iba a registrar el agua que estaba haciendo daño en la referida hacienda de cuia salida y registro pasamos aser [...] y entrando por la cabeceras de dicha hacienda, fuimos con gran trabajo por la mucha agua, dejándose conocer que había mucho tiempo que corría por allí, por los atascaderos que íbamos topando, y aunque el ingeniero y práctico facilitaba quitar el agua y él que declara conociendo la imposibilidad por verla tan derramada y en tan gran trecho que caminamos la mayor parte del día; dixe que solo las fuerzas divinas la quitarían, y viéndolos perdidos en el monte, él que declara los sacó a la mitad del camino de la hacienda Los Marañones [...] y que ésta agua de que está ablando según su inteligencia son derrames y roturas que sale a la punta del Parral, que éste a oído decir que es el Torondoy y que atraviesa por la caveseras de Río Seco y responde" (AGNC, CO, 2, doc. I 4 , f. 448 r.).

36 "[... dijo que él que declara no nació en esta ciudad tiene su residencia en ella y su jurisdicción desde el año veinte [1720] y que tiene bastante conocimiento y práctica de las tierras del valle de Río Seco por aver asistido por aquellos parajes por algunos tiempos y que sabe por averlo oydo desir que antiguamente fueron perdidas las haciendas de dicho valle, y que también oyó decir que los ríos Castro y Torondoy fueron los que perdieron, por los que estos se metieron por la caja del Moyacá, de donde nacieron las inundaciones por no tener caxa suficiente para recibir el agua de dos ríos tan caudalosos, y que por esta razón con el discurso del tiempo que volvieron los ríos a sus madres volvió a quedar la tierra enjuta y comenzaron a fundar nuevas haciendas" (AGNC, CO, 2, doc. 14, f. 449 r.).

37 " [...] desde entonces a esta parte conoce agua en las cabeceras de dichas haciendas, y que está agua es dimanada de haberse roto la caja de Torondoy y atravesar por sobre las haciendas de Río Seco buscando la caja de Moiacá, que está sale a la punta de San Pablo, y de allí tiene varios conductos, y también a este tiempo le dio agua el río de Castro a Moiacá; y como éste no tiene suficiente caja para recibir el abundancia de los dos ríos por ser ambos grandes, dimanó de esto el esparsirce el agua por todos aquellos montes y aserse grandes siénagas, y lagunas que asta oy se mantienen dejando las tierras ynábiles de poderse en ellas cultivar" (AGNC, $\mathrm{CO}$, 2. f. 452 r.). 


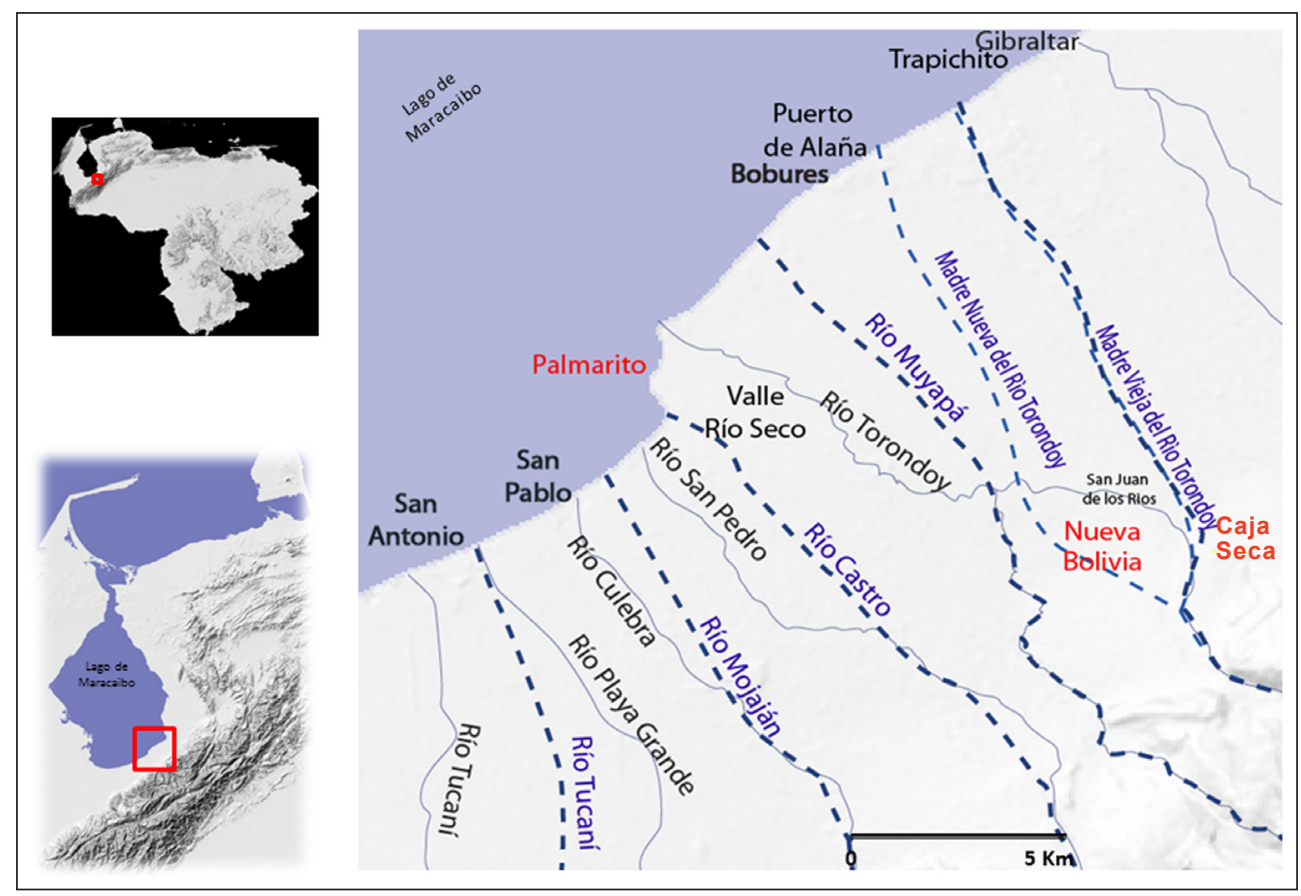

$\rightarrow$ FIGURA 2 .

Cursos de los ríos Torondoy, Muyapá, Castro, Mojaján y Tucaní, I682-I720 Cursos antiguos en líneas punteadas, cursos actuales en líneas.

Fuente: elaboración propia a partir de AGEM, P, t. I-C; Mtrs, tt. I-XXX; AGI, SD, leg. 202; AGNC, co, 2, doc. I4; Nectario María, 57.

haciendas se encharcaban, como se desprende del testimonio emitido entre 1649 y 1650 por Juan Granados Pernía:

[...] pasando el río de Castro, entre él y el Moxaxán, que está adelante del ancón referido y entre dos anegadizos, el uno a la diestra y el otro a la siniestra y la frente a la laguna y de ella mirando el monte adentro hacia la serranía, orillando por los dos anegadizos hasta dar en un caño seco que las divide. (AGI, $E C$, leg 836-c, f. I67 r.-v.) (figura 3)

Las inundaciones originadas por el río Castro continuamente se desaguaban sobre aquellos parajes. En I716 se refería que estaban anegadas y se describía la "madre vieja y seca" del río Castro, lo cual demuestra el cambio de su cauce. Así se desprende del testimonio de Lucas García Cueto, quien señalaba que la hacienda de Marańones estaba a: 
[...] orilla del río Castro viejo [...] cuya estancia se haya anegada y despoblada; y por la parte de los babures a la laguna con la estancia del capitán Diego Cuerbo asimismo despoblada y anegada y atraviesa en medio quedando de una parte a otra el río Moyacan, y [...] por la parte del sur, la madre vieja de Castro lindando con tierras de Lovera que oy son de Francisco de Andrade y con la isla grande, tierras mías, madre seca de Castro viejo de por medio [...]. (AGI, $S F$, leg. 372 , f. 88 r.-v.)

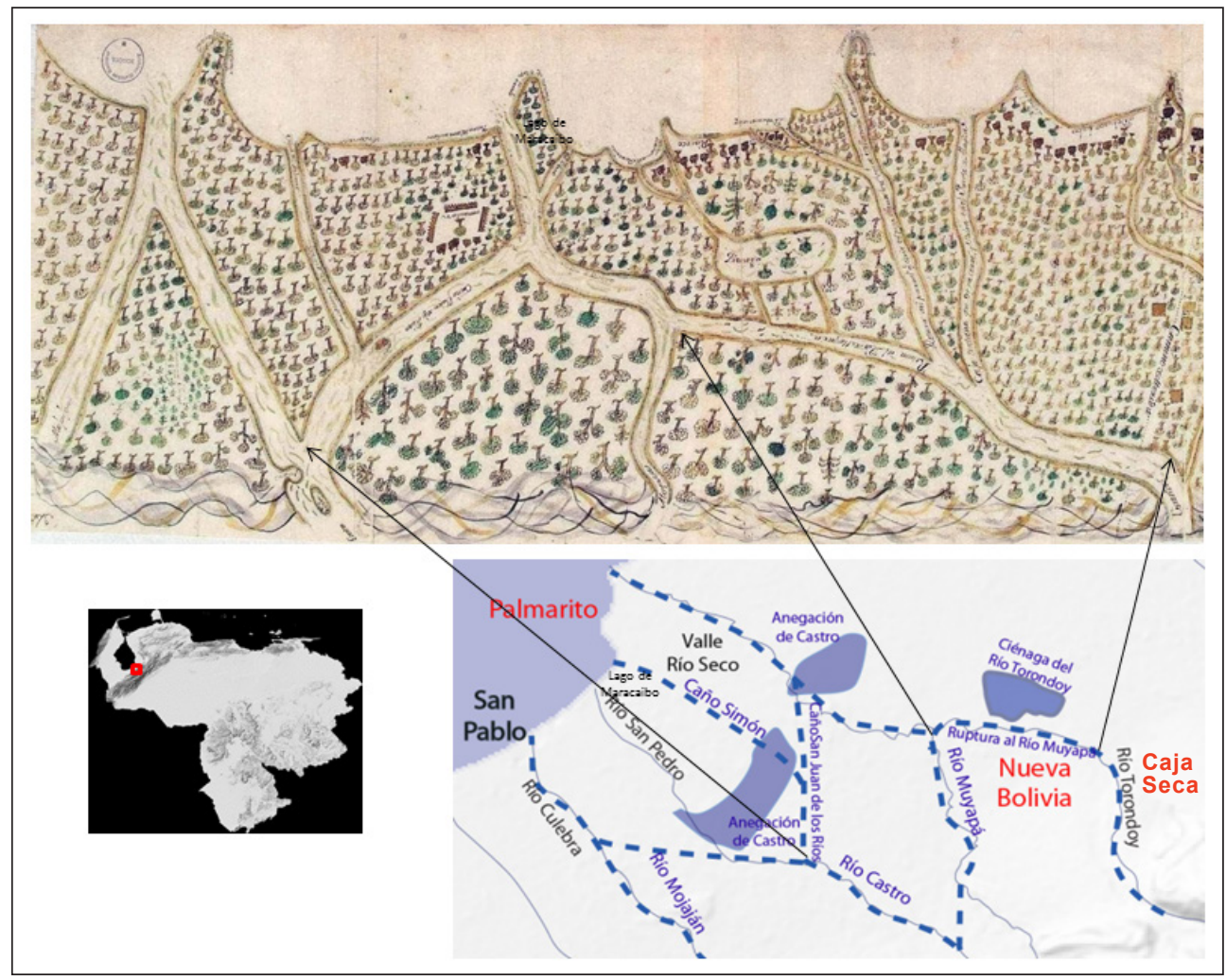

$\rightarrow$ FIGURA 3 .

Cursos de los ríos Torondoy, Muyapá, Castro, Mojaján y los caños de San Juan de los Ríos y Simón, I720-I762

Cursos antiguos en líneas punteadas, cursos actuales en líneas continuas.

Fuente: elaboración propia con base en AGEM, P, t. I-C; Mtrs, tt. I-XXX; AGNC, CO, 2, doc. I4; M 4 , n. ${ }^{\circ} 386-\mathrm{A} ; \mathrm{M} 4$, n. $^{\circ}$ 388-A. 
Años más tarde, en 1720 , se hacía referencia a otros desbordamientos en aquellos predios, especialmente en la misma hacienda de Marañones, que fue totalmente anegada. Por esa razón, Lucas García Cueto decidió donarla a los jesuitas (AGNC, CO, 2, doc I4, f. 230 r.).

Posteriormente, en I748, el río Castro o San Pedro corría perpendicularmente a los ríos Torondoy y Muyapá, “[...] orillado a la serranía y por la parte de arriba se hallaba la subida de la vieja Pascuala [...]" (actual cuesta del Burro), y hacia la parte de abajo estaba la sabana de Jacob (actual Nueva Bolivia) (AGNC, CO, 2, doc. I4, f. 408 r.-v. y f. 4 IO r.-v. ). En ese punto, su curso se tropezaba con "una peña" o "peñón", probablemente producto de un movimiento de masas en una de sus márgenes, ocurrido tal vez en años anteriores ${ }^{38}$. Ese derrumbe desvió parte de sus aguas e impidió que fluyera por su cauce original, que entonces medía en su ancho "[...] 200 varas [...]" (I68 m) (AGNC, CO, 2, doc. I4, f. 408 r.-v. y 4 IO r.-v.). Debido a ello, se originó un nuevo canal, denominado San Juan de los Ríos" ${ }^{39}$, cuyas orillas se ensanchaban en "[...] treinta y cuatro varas y tres cuartos [...]" (28,56 m). De este riachuelo se desprendía otro caño, llamado Simón, cuyo cauce se ampliaba entre ambas riberas en una extensión de "I7 varas" (I4,28 m) (AGNC, CO, 2, doc. I4, f. 408 r.). Esta información permite conocer la extensión del cauce del río Castro durante las crecientes, lo que muestra los incrementos del caudal que discurría por los distintos lechos. Por su parte, las corrientes de San Juan de los Ríos desembocaban en Muyapá y ambos ríos vertían sus aguas al lago de Maracaibo en la punta de San Pablo, mientras el caño Simón se dirigía hacia el Palmar (Palmarito) y drenaba sus aguas en la boca del Palmar. La madre original del río Castro o San Pedro desaguaba en Mojaján o Culebra y este desembocaba en el lago, en la punta de Mojaján ${ }^{40}$ (figura 3).

38 "[...] dijo que es sierto que acompañó a don Lorenso de Aranaga quando fue a registrar el río Castro para saber de dónde le benía el daño a las hasiendas de Río Seco que encontraron las aguas de río Castro que no corrían por su natural caja porque le impedía el dicho peñón su curso, y que por esta razón cargaron a la tierra baja de donde dimanó el daño a aquellas haciendas" (AGNC, CO, 2, doc. i 4 , f. 4 Io v.).

39 "[... la que conoce por caja principal es la de la peña, porque los dos caños de Simón y Juan de los Ríos no son caxas, ni pueden serlo, sino únicamente rupturas que hicieron las aguas de este dicho río [Castro] para buscar su salida a la laguna, por andar perdidas y fuera de su curso natural" (AGNC, $\mathrm{CO}, 2$, doc. 14, f. $4 \mathrm{I} 5 \mathrm{v}$.).

40 " [...] que le consta por haber vivido desde el año treinta y ocho en el puerto antiguo de la hacienda nombrada Marañones de [...] la Compañía de Jesús, que el río Castro corría faldeando la serranía y su desagüe a la laguna lo tenía por el río de Mojaján, y el ancón de Vasave por ser esta su caja principal” (AGNC, CO, 2, doc. I4, f. 407 r.). Véase el mapa de I76I (AGNC, M 4, n. ${ }^{\circ} 388-A$ ). 
Esos cauces modificaron nuevamente su curso a partir de 1748 , cuando sobrevino el desvío de los ríos San Pedro y Torondoy. Estos escurrieron por el canal del Muyapá y produjeron otra inundación que afectó notoriamente a la hacienda de Marañones. Tal situación se mantuvo por los siguientes diez años, con ciénagas que amenazaban de ruina a Marañones, como lo describe Pedro Millán en 1762 al decir que se habían perdido "casi cuarenta mil árboles de cacao con los correspondientes platanares, así pertenecientes a esta casa, como a los criados [...] con evidente peligro de la total ruina de esta nuestra única y sola hacienda"4i (figura 3).

\section{La resiliencia}

Durante el periodo estudiado, la población estuvo atenta a las modificaciones en el caudal y la velocidad de las corrientes de los acuíferos, con la finalidad de establecer y delimitar las zonas de inundables ocasionadas por las riadas, y se pensó que esos daños se limitaban a las márgenes de los cursos; es decir, los propietarios consideraron que esos perjuicios se evitaban con desalojar las zonas expuestas a las inundaciones, pues desconocían las modificaciones en las rutas que seguían esos afluentes. Por esa razón, optaron por abandonar las áreas inundables, a las que calificaron como "desechados o anegadizos", como ya se pensaba en 1623 cuando se afirmaba que esas "tierras que desde hace diez o doce años de beneficio se an perdido y secado los árboles de cacao [...] y es dudosa su permanencia" (aGEM, $P$, t. viII, ff. I3 v.-I5 v.).

Los hacendados procedieron a desarrollar sus cultivos sobre extensiones que se creía estaban a salvo de los temibles aluviones destructores de las plantaciones. Esas apreciaciones determinaron la existencia de zonas altamente codiciadas por sus inestimables condiciones de fertilidad, como se atestiguaba en la próspera hacienda de Juan Dávila y Rojas cuyas tierras se inventariaron en el banco de Santa Lucía y el Pepeo con II.ooo árboles de cacao, en el de Babures 5.Ioo, en el de Santa Cruz 8.200 y el de San Isidro 8.60o (AGEM, Mtrs, t. X, ff. 390 r.-39I v.).

La situación se mantuvo inalterable hasta la ocurrencia del deslave de I674, el cual modificó las condiciones del suelo al depositar sustratos arenosos

4I AGNC, $\mathrm{CO}$, 2, doc. I4, f. 567 v. Véase el mapa de I76I (AGNC, M 4, n. ${ }^{\circ}$ 388-A). 
que sepultaron la capa vegetal sumamente fértil que existía, especialmente en el valle de Castro. Por ello, las siembras de cacao fueron sustituidas por caña de azúcar (AAM, $s$, caja I, L. R., f. I7 r.), lo cual representó la adaptación de la población a las modificaciones ocasionadas por el desastre sobre sus actividades económicas.

Aunque el río Castro con relativa frecuencia inundaba la hacienda de los Marańones, se hizo un esfuerzo tenaz por mantener productivas esas fértiles tierras, como se refirió en 1752 cuando se había construido una ranchería formada por 17 casas y una capilla y se habían sembrado 5.600 matas de plátano y ioo fanegas de maíz, valoradas en 200 pesos, tanto para el consumo de los esclavos como para su venta. En principio, se habían plantado 500 árboles de cacao, con proyección para establecer un tablón en el que se habrían de plantar 8.000 adicionales. Y también se había realizado la composición y apertura de caminos. En la construcción y el proceso de siembra de la hacienda se habían invertido I.485 pesos y 6 reales (AAM, $s$, caja I, L. R., f. I7 r.-v.). De ese modo, Marañones avanzó rápidamente a una próspera unidad de producción que contaba con más de 80.000 árboles de cacao, no obstante los incontables problemas causados por las riadas del Torondoy y del Castro.

En una respuesta consensuada, los hacendados de los valles de Bobures y Castro aunaron esfuerzos para canalizar los cursos de los ríos, a fin de evitar las indeseadas inundaciones. Con esa finalidad, en 1752 hicieron elevadas inversiones en la construcción de muros que mantuvieran al río Castro fluyendo por su "madre vieja" y evitar de esa forma que se produjeran las temidas inundaciones. Sin embargo, esas previsiones estaban distantes de proporcionarles la seguridad deseada ante esas eventuales amenazas, debido a la vulnerabilidad que se derivaba del desconocimiento de la tecnología capaz de hacer frente a esos eventos. Ello se hizo patente cuando las construcciones realizadas fueron superadas por la fuerza de las crecidas.

Es fundamental resaltar y describir la actuación diferenciada de los pobladores de los valles en estudio, en especial después del desastre ocurrido a finales del siglo XVII, cuyos efectos fueron percibidos desigualmente por merideńos y marabinos, y conllevaron actuaciones diametralmente opuestas. En efecto, para los emeritenses las secuelas del sismo y deslave fueron devastadoras porque perdieron la mayor parte de los cacahuales y de los esclavos, los cuales perecieron durante esos funestos eventos. Ello determinó el progresivo abandono de sus haciendas y ocasionó el avance indígena, especialmente en los valles de Santa María y San Pedro (Ramírez, La tierra Ioo-I40). 
Esa deplorable situación fue denunciada por el ayuntamiento emeritense ante el Consejo de las Indias, con el propósito de que se socorriera a la población, en vista de las adversas circunstancias que enfrentaba, e impedir las visitas de los indeseados jueces de comisión. Por esa razón, en i688 los capitulares acreditaron al procurador de Maracaibo con el fin de que los representara ante el gobernador provincial y atestiguara la lamentable ruina en que se hallaba Mérida, además de intentar impedir la llegada de jueces, pues dado el caso los merideños tendrían que asumir los emolumentos de esos funcionarios (AGI, $S D$, leg. 202, f. 5). Esto se reiteró en I7II (AGEM, DH, ff. IO r.-I4 v.).

A diferencia de los merideńos, los marabinos reiniciaron los procesos de cultivo del cacao y otros productos de subsistencia. De igual manera, hicieron inversiones de capital destinado a la adquisición de otros predios y mano de obra, aunque estuvieran amenazados ${ }^{42}$. Por esa razón, en 1716 se reiteraba que a causa de las inundaciones estaban "experimentando las pérdidas de dichas haciendas cada día y por ello [debían] el mudar los plantajes de un sitio a otro [...]" (AGI, $S F$, leg. 372, f. 2I v.), lo cual demuestra que aun cuando los propietarios estaban perjudicados con el "atraso y menoscavo" que les ocasionaban esas riadas, también se adaptaban a las contingencias que enfrentaban.

Ello se debió a la necesidad de víveres destinados a alimentar a la población de Maracaibo, cuyos comestibles se producían en los mencionados valles, y también mantener la producción del cacao, cuya rentabilidad era muy elevada, lo cual determinó hacer sostenible el proceso productivo agrícola. En ese sentido, se refieren en ese espacio, entre otras haciendas que se mantuvieron productivas durante el siglo xviII, la de los Ancones en Río Seco, propiedad de Pedro Joseph Antúnez Pacheco, que contabilizaba Ioo.0oo árboles de cacao; la de José Antonio Basave en Culebras, que tenía unos 30.000 árboles, y la de Marañones, que se expandía sobre 23 estancias con más de 80.000 árboles y era habitada por aproximadamente 70 esclavos.

El conocimiento de las autoridades provinciales sobre la vulnerabilidad y los eventuales riesgos a que estaba expuesta esa llanura, producto de las continuadas inundaciones, se manifestó en I77I, cuando se diseñaron e implementaron las previsiones que fueron adoptadas para la construcción del templo de San Pedro, en las que se evidencia el conocimiento de las autoridades provinciales 
sobre las amenazas y el riesgo. En atención a ello, se planificó una construcción sismorresistente, a salvo de las inundaciones, como se desprende de las instrucciones emitidas por el gobernador Alonso del Río para

[...] hacer una iglesia proporcionada de mampostería, mescla real y maderas de las mejores calidades para su techumbre, y seguridad no solo de temblores, sino de la voracidad de la laguna que está en parage de poder lastimarla, y del modo que se precave será difícil que llegue a ocurrir tal daño [...] (AGNC, FI, 20, doc. 35, ff. 799 r.-80o r.)

De acuerdo con esas disposiciones, el templo de San Pedro se edificó sobre una explanada elevada entonces, aproximadamente a una altura de 1,50 metros sobre el nivel de costa de la laguna, que se había formado con los depósitos de arena acarreados por los ríos, sedimentados en las riberas de lago, lo cual aparentemente ponía al templo a salvo de las aguas. De la misma forma, se previó que los zócalos del templo debían ser construidos "[...] de cal y piedra que profunden las tierras cinco cuartas [I,I4 m], y de ancho seis dichas [...] [I,37 m]" (AGNC, FI, 20, doc. 35, ff. 782 r.-784 r.), o bien "[...] cinco quartas poco más o menos según hallaremos el fuerte del terreno, y lo mismo de ancho de piedras y cal [...]" (AGNC, FI, 20, doc 35, ff. 789 v.-79I r.). Lo anterior evidencia la preocupación de las autoridades provinciales por construir edificaciones sismorresistentes y a salvo de las inundaciones.

\section{Conclusiones}

La expansión de la sociedad agraria en los valles de los ríos Castro o San Pedro, Mojaján o Culebra y Torondoy en el sur del lago de Maracaibo (Venezuela), durante los siglos XVI y XVII, fue impulsada por su fertilidad, la cual se derivaba de las ingentes cantidades de agua que depositan los afluentes que discurren por esa llanura, propicia para los cultivos del cacao. Dichas excepcionales condiciones motivaron a los hispano-criollos a establecer sus haciendas productoras, orientadas al mercado caribeño. Esos mismos recursos hídricos, no obstante, también representan amenazas, porque los elevados índices de pluviosidad, velocidad y arrastre de los afluentes ocasionan inundaciones periódicas, modificaciones del curso de los afluentes y anegaciones de espacios cultivados. Y fue esto lo que causó la pérdida de los cultivos de cacao, luego de los eventos referidos en este escrito. Esas amenazas se vieron potenciadas por las vulnerabilidades 
económicas, políticas, técnicas y culturales presentes en la población que habitaba ese espacio geográfico. Durante la ocurrencia de los precursores de 1673 y el sismo y deslave de 1674 , dichas vulnerabilidades contribuyeron al desastre que produjo la destrucción del aparato productivo y la pérdida de vidas, lo cual afectó de forma definitiva el hábitat y el paisaje cultural de los valles estudiados.

Las amenazas mencionadas continuaron manifestándose sucesivamente durante la primera mitad del siglo Xviı por medio de inundaciones cíclicas, de suerte que la población continuó en riesgo, en tanto que el aparato productivo sufrió un daño permanente. Asimismo, esos devastadores efectos también motivaron el proceso de resiliencia, primero con el abandono de áreas que se consideraban improductivas después del sismo y del deslave, y luego con la progresiva reconstrucción de las haciendas y la rotación de los cultivos, que nuevamente se vieron afectadas por los aluviones, en especial durante el siglo xvirI. Adicionalmente, se llevaron a cabo actuaciones políticas de solicitud de socorro a la Corona española para que se realizaran intentos de canalización de los ríos y, de igual manera, se adoptaron medidas por parte de las autoridades para evitar que las edificaciones importantes fueran afectadas por esos adversos efectos.

\section{\$ \\ B I B L I O G R A F Í A}

F U E N T ES PR I MARIAS

\section{A. Archivos}

Archivo Arquidiocesano de Mérida, Mérida, Venezuela (AAM). Seminario $(s)$.

Caja 1: Libro de recibo de la Compañía de Jesús.

\section{Archivo General del Estado Mérida, Mérida, Venezuela (AGEM).}

Documentos Históricos (DH).

Expediente promovido por el procurador don Cristóbal de Gámez y Costilla. Testimonios de las autoridades eclesiásticas. Mérida, 24 de febrero de 1711, ff. 10 r.-14 v. 
Protocolos $(P)$.

TT. I al C

T. viII. Poder de Juan Pérez Cerrada. Mérida, 23 de enero de 1623, ff. 13 v.-15 v.

T. IX. Testamento de Fernando Cerrada. Mérida, 25 de diciembre de 1624,

ff. 76 r. $-82 \mathrm{v}$.

T. XI. Carta de donación. Mérida, 13 de septiembre de 1628, f. 320 r.-v.

T. xxx. Carta de venta. Mérida, 21 de noviembre de 1676, ff. 234 r.-236 v.

T. xxx. Testamento de Magdalena Ximeno de Bohórquez. Mérida, 30 de julio de 1676 , ff. 186 r.-189 r.

T. xxxvi. Testamento de Isabel Ana de Ribas. Mérida, 27 de diciembre de 1684 , ff. 97 r.-116 v.

Mortuorias (Mtrs).

T. x. Mortuoria Juan Dávila y Rojas. Mojaján, 29 de septiembre de 1667, ff. 390 r.-391 v.

\section{Archivo General de Indias, Sevilla, España (AGI).}

Escribania de Cámara (EC).

Legajo 836-c. Visita de Modesto de Meller y Diego de Baños y Sotomayor. 1655-1657. Composiciones.

Mapas y planos de Venezuela (MPV).

3B "Laguna de Maracaybo. 1642-2-5”.

57, 1682, 22,2. "Carta Corográfica de la Laguna de Maracaibo, donde se demuestran laz entradas de loz, sitios y fuerzas de las ciudades, lugares y puertos de lagunillas demostrado por escala de a, b y c”.

286 "Descripción de la Laguna de Maracaibo, sacada por escala plana y petipie de leguas castellanas, con las ciudades, pueblos, balles, puertos y castillos que encierran en si por ABC".

Santo Domingo (SD).

Legajo 202. Informe del procurador general de Mérida José García de Ambas. Mérida, 20 de abril de 1688.

Legajo 668. Comunicación del Cabildo de Maracaibo. Maracaibo, 25 de mayo de 1716 , ff. 3 v. -5 r. 
Santa Fe $(S F)$.

Legajo 372. Expediente de don Diego Manuel de Eguiazabal. Composición de don Lucas García Cueto. Maracaibo, 16 de octubre de 1716, f. 88 r.-v.

Legajo 372. Expediente de don Diego Manuel de Eguiazabal. Comunicación de las autoridades eclesiásticas de San Antonio de Gibraltar. San Antonio de Gibraltar, 25 de junio de 1716, f. 21 v.

\section{Archivo General de la Nación Colombiana, Bogotá, Colombia (AGNC).}

Sección Colonia

Curas y Obispos (co).

T. 2, doc. 14. Valle de Río Seco, pleito de jesuita por servidumbre de aguas.

Fábrica de Iglesias (FI).

T. 20, doc. 35. Santa María y San Pedro reconstrucción de iglesias. Comunicación del Gobernador don Alonso del Río y Castro al Virrey don Pedro Messía de la Cerda. Maracaibo, 18 de noviembre de 1771, ff. 799 r. -800 r.

Milicias y Marina ( $\mathrm{MM})$.

T. 137. Información del Cabildo, Justicia y Regimiento de la ciudad de Mérida para la Real Audiencia de Santa Fe de Bogotá. Mérida, 24 de abril de 1674, f. 698 r.-v.

Misceláneas $(M s)$.

T. 149. Autos fechos en razón de la mayordomía del hospital de Jesús Nazareno en la ciudad de Gibraltar. Notario Juan de Ovando Gibraltar, 10 de septiembre de 1674 , f. 78 r.

Mapas y planos

Mapoteca 4, n. ${ }^{\circ}$ 386-A (M). "Mapa elaborado por Pedro Josep Antúnez Pacheco", 1760.

Mapoteca 4, n. ${ }^{\circ}$ 388-A (M). "Mapa elaborado de por fray Fernando Mayorga en 1761 ".

Biblioteca Nacional Biblioteca Febres Cordero, Mérida, Venezuela (BNBFC). Cabildo. Mercedes de Tierra. (CMT). Caja iı, doc. I. Merced a Juana Bedoya. Mérida, 26 de abril de i627, f. I8I r.-v. 


\section{F U E N T ES SECUNDARIA S}

Calvente Arturo. Resiliencia un concepto clave para la sustentabilidad. Buenos Aires: Programa de Difusión e Investigación en Sustentabilidad, Centro de Altos Estudios Globales, Universidad Abierta Interamericana, 2007.

Campo del Pozo, Fernando. Historia documentada de los agustinos en Venezuela. Caracas: Academia Nacional de la Historia, i968.

Cardona A., Omar Darío. "Evaluación de la amenaza, la vulnerabilidad y el riesgo. Elementos para la ordenación y planeación del desarrollo". Maskrey, pp. 5 ${ }^{\mathrm{I}} 74$.

Daza, Samir Joaqui y Apolinar Figueroa Casas. "Factores que determinan la resiliencia socioecológica para la alta montaña andina”. Revista Ingenierías Universidad de Medellin, vol. I3, n. ${ }^{\circ} 25,2014$, pp. 47-55.

Espinosa, Antonio. "Hidrografía. La cuenca del lago de Maracaibo. Principales ríos. Principales cuencas. Aguas superficiales. Aguas subterráneas”. Sinopsis fisiográfica de la región zuliana. Caracas: Academia Nacional de Ciencias Económicas, I992, pp. 89-II3, http://ance.msinfo.info/bases/biblo/texto/libros/EA.I992.a.5.pdf.

Febres Cordero, Tulio. "Documentos para la historia del Zulia en la época colonial”. Obras completas, por Tulio Febres Cordero, t. IV. Bogotá: Antares, I960, pp. I28-I30.

Folke, Carl. "Resilience: The Emergence of a Perspective for Social-Ecological Systems Analyses". Global Environmental Change, vol. I6, n. ${ }^{\circ}$ 3, 20o6, pp. 253-267, https://doi.org/Io.Ior6/j.gloenvcha.2006.04.002.

Folke, Carl et al., "Resilience and Sustainable Development: Building Adaptive Capacity in a World of Transformations". AMBIO: A Journal of the Human Environment, vol. 3 I, n. ${ }^{\circ}$, 2002 , pp. 437-440.

Gallopin, Gilberto. Sostenibilidad y desarrollo sostenible. Un enfoque sistémico. Santiago de Chile: Cepal, 2003.

García Acosta, Virginia, coordinadora. Historia y desastres en América Latina, vol. I. Red de Estudios Sociales en Prevención de Desastres en América Latina. Ciudad de México: Ciesas, I996.

Goldstein, Isaac et al. "Sustentabilidad de los paisajes andinos de Venezuela. Emergencias territoriales prioritarias en la conservación del agua”. Revista Geográfica Venezolana, vol. 53, n. ${ }^{\circ}$ 2, 20I2, pp. 213-238.

Hercer, Hilda María y María Mercedes di Virgilio. "Buenos Aires inundable del siglo xıx a mediados del siglo xx”. García Acosta, pp. 67-гоo. 
Ize, Lema Irina. "Resiliencia, glosario, conceptos, resiliencia costera bibliografía”. Documento de trabajo, Laboratorio Nacional de Resiliencia Costera, http://www. lanresc.mx/intranet/noticias/Documento\%2ode\%2otrabajo\%2oresiliencia.pdf.

Lavell, Allan et al. La gestión local del riesgo: nociones y precisiones en torno al concepto y la práctica. Ciudad de Guatemala; Ciudad de Panamá: Centro de Coordinación para la Prevención de los Desastres Naturales en América Central (Cepredenac), Programa de las Naciones Unidas para el Desarrollo (PNUD), 2003.

Maskrey, Andrew, compilador. Los desastres no son naturales. Buenos Aires: Red de Estudios Sociales en Prevención de Desastres en América Latina, I993.

Moberg, Fredrik. ¿Qué es la resiliencia? Una investigación sobre el sistema socioecológico. Estocolmo: Stoschkolm Resiliencie Centre, 201 .

Nectario María (hno.). Mapas y planos de Maracaibo y su región 1499-I820. Madrid: Embajada de Venezuela, I973.

Palme, Christl y Rogelio Altez. "Los terremotos de i673 y I674 en los Andes venezolanos". Revista INCI, vol. 27, n. ${ }^{\circ}$ 5, 2002, pp. 220-226.

Ramírez Méndez, Luis Alberto. "El cultivo del cacao venezolano a partir de Maruma”. Historia Caribe, vol. x, n. ${ }^{\circ} 27,2015$, pp. 69-Ior, http://dx.doi.org/Io.15648/ hc. $27 \cdot 2015 \cdot 3$.

---. La tierra prometida del sur del lago de Maracaibo. De su misma sangre. La frontera indigena. Maracaibo: Universidad Nacional Experimental Rafael María Baralt, 2015.

Ramírez Méndez, Luis Alberto y Reina Aranguren. "Los efectos de los sismos de 1673 y 1674 en el sur del lago de Maracaibo”. Nuestro Sur, año 7, n. ${ }^{9}$, 2016, pp. 95-I26.

“Resiliencia: ¿proceso de superación de la adversidad?”, http://notas.nezit.com.ar/ resiliencia.htm.

Roa, José Gregorio. "El sistema fluvial de la planicie Motatán-lago de Maracaibo. Una introducción a su análisis cartográfico histórico". Revista Geográfica Venezolana, vol. 45, n. ${ }^{\circ}$ I, 2004, pp. 67-9o.

Teixeira, Simonne. "Paisaje cultural y representaciones de la naturaleza en dos cuencas hidrográficas en el siglo xıx (Brasil y España)”. Historia Caribe, vol. x, n. ${ }^{\circ}{ }_{2} 6$, 2015, pp. IO7-I33, http://dx.doi.org/Io.15648/hc.26.2015.5.

Twigg, John. "Características de una comunidad resiliente ante los desastres. Nota guía”, http://www.benfieldhrc.org/disaster_studies/projects/ communitydrrindicators/community_drr_indicators_index.htm.

Wilches-Chaux, Gustavo. "La vulnerabilidad global”. Maskrey, pp. II-44. 